\title{
Identidad y compensación en el nacionalismo cultural alemán en la época de la Republica de Weimar
}

\author{
Héctor del Estal Sánchez
}

Recibido: 10 de enero de 2018 / Aceptado: 09 de octubre de 2018

Resumen. Bajo el signo de 1918 se produjo en Alemania una revitalización compensatoria del nacionalismo cultural heredero del fenómeno de la recepción de Schopenhauer a mediados del siglo XIX que, mediante la identificación de un enemigo interno (el judaísmo), trató de dar respuesta a una crisis de identidad. En este trabajo estudiamos esta hipótesis a través del análisis de una polémica que se dio en torno a la Schopenhauer-Gesellschaft a raíz del panfleto de Maria Groener Schopenhauer und die Juden (1920).

Palabras clave: Schopenhauer; nacionalismo cultural; pesimismo; compensación; antisemitismo; República de Weimar.

\section{[en] Identity and Compensation in German Cultural Nationalism in the era of the Weimar Republic}

\begin{abstract}
In 1918, Germany was experiencing a counterbalancing revitalisation of cultural nationalism, successor of Schopenhauer's reception phenomenom from the mid-nineteenth century that tried to respond to an identity crisis through the identification of an internal enemy (Judaism). In this paper, we test this hypothesis through the analysis of the controversy around Schopenhauer-Gesellschaft resulting from Maria Groener's pamphlet Schopenhauer und die Juden (1920).
\end{abstract}

Keywords: Schopenhauer; cultural nationalism; pessimism; compensation; antisemitism; Weimar Republic.

Sumario: 1. Una polémica en el seno de la Schopenhauer-Gesellschaft en torno al significado de Schopenhauer para la cultura alemana de los años 20;2. El nacionalismo cultural como movimiento compensatorio: El pesimismo de Schopenhauer y las sombras de 1848; 3. La construcción de la identidad y la dinámica amigo-enemigo: Eduard von Hartmann bajo la luz de 1871; 4. Nacionalismo cultural en clave antisemita: Maria Groener y la lectura racista de Schopenhauer después de la Primera Guerra Mundial; 5. Conclusión; 6. Referencias bibliográficas.

Cómo citar: Estal Sánchez, H. del (2019): “Identidad y compensación en el nacionalismo cultural alemán en la época de la Republica de Weimar", en Revista de Filosofía 44 (1), 43-59.

\footnotetext{
1 Universidad de Salamanca hedesa@usal.es
} 


\section{Una polémica en el seno de la Schopenhauer-Gesellschaft en torno al significado de Schopenhauer para la cultura alemana de los años 20}

La Schopenhauer-Gesellschaft [Sociedad-Schopenhauer] ${ }^{2}$ fue fundada en 1911 por Paul Deussen, archiconocido intérprete de la filosofía schopenhaueriana e indólogo. El objetivo fundamental de la sociedad fijado por él y sus colaboradores, Josef Kohler $^{3}$ y Arthur von Gwinner ${ }^{4}$, era fomentar mediante la divulgación y propagación del pensamiento de Schopenhauer un «estudio científico de la metafísica» que alejase la «superstición y el materialismo vulgar» del «espíritu del país» ${ }^{5}$. Sin embargo, si se quería cumplir este cometido -afirmaba Deussen en Wie ich zu Schopenhauer kam [Cómo llegué a Schopenhauer] (1911)- la SG no debía ser un órgano «que sirv[iese] para [realizar] una propaganda unilateral [de la filosofía de Schopenhauer], sino [...] para buscar mediante el intercambio general de ideas un entendimiento sobre los problemas que la doctrina de Schopenhauer ha planteado al espíritu humano» (Deussen 1911, p. 18). Esto debía hacerse, además, respetando la pluralidad de las opiniones que sus colaboradores pudiesen aportar: «La libertad espiritual ante todas las tradiciones que el genio de Schopenhauer ha difundido en círculos cada vez más y más amplios de nuestra patria debe darse a conocer también en las contribuciones a nuestros anuarios» (Deussen 1911, p. 19).

Con ello se pone de manifiesto que la SG estuvo atravesada en sus primeros años por el espíritu liberal de Deussen respecto a las cuestiones científicas: por una parte, en lo referente al contenido del Schopenhauer-Jahrbuch [Anuario-Schopenhauer] ${ }^{6}$, se estableció que éste no estaría restringido únicamente a trabajos de índole científica, sino que también abriría sus puertas a contribuciones artístico-literarias; y por otra parte, en lo que respecta a la dirección filosófica del mismo, Deussen alentaba a una continuación de la senda de Schopenhauer yendo más allá de él. En este último sentido, afirmaba:

Kant y Schopenhauer son y siguen siendo nuestros maestros, pero no en el sentido de que juremos lealtad a sus palabras, sino en la medida en que a ambos les reconocemos, en un sentido amplio, lo que Schopenhauer dijera de Kant: que la niebla que estaba ante nosotros antes de ellos se ha disipado [y], por lo tanto, ahora nosotros consideramos a la naturaleza misma, tanto la interior como la exterior, como nuestra maestra; y no somos ya propensos a tomar más sus revelaciones con los prejuicios de un espíritu turbado [que es incapaz de ver con claridad] (Deussen 1911, p. 19).

Este espíritu liberal en lo científico permeó en la actitud que bajo su dirección mantuvo la SG ante los problemas político-sociales de su tiempo; y también salió a relucir en los años de la Primera Guerra Mundial, durante los cuales la SG mantuvo una actitud internacionalista y pacifista alejada tanto de los sentimientos anti-

A partir de ahora, SG.

Josef Kohler (1849-1919) fue un jurista y profesor en las Universidades de Wurzburg y Berlín que participó muy activamente en la fundación de la $S G$.

4 El banquero Arthur von Gwinner (1856-1931), hijo de Wilhelm von Gwinner (el famoso biógrafo y amigo de Arthur Schopenhauer) fue también uno de los colaboradores de Deussen en la fundación de la SG.

Cfr. Hansert (2010), pp. 31 y s

6 A partir de ahora, SJb. 
franceses o anti-ingleses como de las expresiones de exaltación ultranacionalista ${ }^{7}$.

Sin embargo, a pesar de los esfuerzos de Deussen, las consecuencias derivadas del final de la Gran Guerra también tuvieron su eco dentro de la SG y desembocaron en la década de los 20 en lo que terminó por denominarse «el caso Groener» ${ }^{8}$. La controversia que este «caso» generó entonces había encontrado ya en los años anteriores el germen que daría lugar a su expresión: en 1914 y en 1918 un grupo de miembros de la SG exigió una mayor rigurosidad científica para las contribuciones al $\mathrm{SJb}$ reclamando así una «profesionalización» de la actividad editorial de la SG.

Maria Groener ${ }^{9}$ aprovechó este ambiente para atacar por escrito a la SG y en 1916, en una reseña del cuarto número del SJb publicada en Archiv für die Geschichte der Philosophie [Archivo para la historia de la filosofia], se rebelaba contra el espíritu fundacional de Deussen proponiendo un nuevo motto para guiar a los miembros de la sociedad schopenhaueriana: «No [ir] más allá de él [de Schopenhauer], sino [profundizar] más en él» (Groener 1916, p. 143). Lo que se escondía realmente bajo esta llamada de atención a los miembros de la SG no se dejaría ver con algo más de claridad hasta 1918, cuando Groener sacó a la luz un panfleto titulado An die Mitglieder der Schopenhauer-Gesellschaft [A los miembros de la Sociedad-Schopenhauer]. En él Groener insistía en la necesidad de elevar los estándares científicos del SJb, criticaba la abundancia de contribuciones «diletantes» en él, atacaba a sus autores -los cuales eran en su mayoría o bien judíos o bien demócratas convencidos- y proponía restringir el número de contribuciones al anuario de la sociedad. Hacia el final del texto volvía a enfrentarse al espíritu de Deussen afirmando:

Sí, soy ortodoxa, pero ortodoxa en legítima defensa, no por principio. [...] ¡Soy ortodoxa en legítima defensa porque en nuestra sociedad [la SG], en las raíces de nuestro árbol frutal, ha aparecido algo de podredumbre! Una podredumbre radical que descompone la fuerza vital e impide la posibilidad de toda efectividad [en la sociedad] (citado según Ciracì 2011a, p. 177).

El árbol cuyos frutos tendrían que ser la «fuerza vital [Lebenskraft]» y la «posibilidad de efectividad [Wirkungsmöglichkeit]» de los que habla Groener no es otro aquí que el nacionalismo alemán; y sus raíces, el pensamiento de Schopenhauer, el cual estaba siendo tergiversado -según su opinión- por los intentos de ir más allá de él.

La propuesta final de Groener, en la que se prefiguraría la idea que está detrás del texto detonante de la polémica, era expresada con estas palabras: «Schopenhauer en su extensión -como esperanza para los que sufren; Schopenhauer en su altitud -como filosofía rectora de la universidad del porvenir» (citado según Ciracì 2011b, p. 44). Aquella exigencia de una mayor profundidad en el estudio de la filosofía schopenhaueriana ocultaba detrás de sí, como se demostraría más tarde, una lectura racista de la teoría schopenhaueriana del genio en la que las consideraciones raciales

\footnotetext{
Cfr. Cirarcì (2011b), p. 32.

Cfr. Ibid., p. 59.

La cofundadora de la Neue Deutsche Schopenhauer-Gesellschaft, Maria Freyburger (Groener) (1882-1937), fue una discípula del schopenhaueriano Gustav Wagner y una de las primeras colaboradoras de la SchopenhauerGesellschaft fundada por Deussen. Maria Freyburger nació en una familia acomodada de Innsbruck y contrajo matrimonio con Alfred Groener, jefe del Banco Ruso-Chino en San Francisco. Tras la muerte de éste, se convirtió en profesora de enseñanza superior en Karlsruhe.
} 
y antisemitas se entremezclaban con una visión jerárquica de la actividad intelectual tanto dentro como fuera de la $\mathrm{SG}^{10}$.

Enarbolando estas ideas, Groener y Johann Emil Weber ${ }^{11}$ consiguieron reunir un grupo de miembros afines que se denominó a sí mismo el «partido reformador [Reformpartei]» de la SG. Esta división interna de la sociedad terminó por materializarse en 1920, un año después de la muerte de Deussen, con la aparición en la editorial Deutscher Volksverlag ${ }^{12}$ de otro panfleto de Maria Groener titulado Schopenhauer und die Juden [Schopenhauer y los judios]. El contenido del texto, claramente racista y ultranacionalista, ponía en claro lo que en los anteriores escritos solo se insinuaba: lo que estaba detrás de las críticas a la falta de rigor científico del $\mathrm{SJb}$ era en realidad el antisemitismo. Éste se manifestaba ahora sin ningún tapujo en la idea fundamental del panfleto: Groener sostenía que la SG se había «judaizado» poniendo en peligro no solo la filosofía de Schopenhauer, sino también la «germanidad». La editorial envió propaganda del libro a todos los miembros de la SG y la reacción de ésta no tardó en producirse: en mayo de 1920 una circular interna de la sociedad se posicionaba oficialmente en disconformidad con el texto de Groener y recordaba a sus miembros que la SG tenía un perfil estrictamente científico alejado, en todo caso, de las posiciones políticas de partido. La preocupación en el seno de la sociedad por la publicación de Groener se puede apreciar en una carta de Hans Zint ${ }^{13}$ dirigida a Franz Mockrauer ${ }^{14}$ en la que expresaba lo siguiente: «Respecto al libro, ahora veo que las cosas son más graves de lo que se evidenciaba en la propaganda. [...] Schopenhauer es interpretado [...] como un racista de la peor calaña y, más de una vez, de un modo totalmente distorsionado» (citado según Ciracì 2011b, pp. 54 y s.).

La paciencia de la SG respecto al «caso Groener» se vio colmada finalmente ese mismo año, cuando Johann Emil Weber publicó otro panfleto titulado Wie Lange noch? (Quousque tandem?) Eine Programmschrift zur Neuordnung der Schopenhauer-Gesellschaft [¿Hasta cuándo? (Quosque tandem?) Un escrito programático para la reorganización de la Sociedad-Schopenhauer] en el que, reproduciendo las opiniones de Groener, se quejaba de que la dirección de la SG no se mostrase favorable a la interpretación racista de Schopenhauer y de que aceptase entre sus miembros a no-alemanes ${ }^{15}$. La SG decidió entonces expulsar tanto a Maria Groener como a Emil Weber.

El resultado inmediato de esta polémica fue la fundación en 1920, por parte de los dos miembros expulsados, de la Neue Deutsche Schopenhauer-Gesellschaft [Nueva

10 Cfr. Ciracì (2011b), p. 44. Las últimas consecuencias de esta interpretación de Groener se pondrían de manifiesto precisamente en el cuarto apartado del panfleto Schopenhauer y los judios (1920), titulado Los judios en su producción intelectual, en el que a través de un pseudoanálisis de los escritos de Frauenstädt los prejuicios antisemitas y raciales son el hilo argumentativo para una supuesta demostración filosófica y científica de la inferioridad intelectual de los judíos (cfr. Groener 1920, pp. 27-38).

11 El periodista Johann Emil Weber ( $i^{-}$-), primo de Maria Groener, fue uno de los primeros miembros de la Schopenhauer-Gesellschaft y cofundador, con aquella, de la Neue Deutsche Schopenhauer-Gesellschaft.

12 Deutscher Volksverlag fue fundada 1919 en München con una línea estrictamente antisemita. Esta editorial sería la responsable de sacar a la luz, entre otros textos de la misma índole, el semanario antisemita de Alfred Rosenberg Der Weltkampf y distintas ediciones de los discursos de Adolf Hitler.

13 Hans Zint (1882-1945), jurista de formación, fue editor del SJb en 1926 y presidente de la SG entre 1924 y 1936.

14 Franz Mockrauer (1889-1962) fue un pedagogo y periodista que estuvo al cargo de la dirección de la SG entre 1920 y 1924.

15 Cfr. Ciracì (2011b), pp. 56-59. 
Sociedad-Schopenhauer Alemana] ${ }^{16}$. El objetivo y sentido de la misma era claro: llevar a cabo un estudio de Schopenhauer desde el punto de vista de la völkische Bewegung ${ }^{17}$. Dentro de este movimiento la NDSG encontró respaldo en periódicos como el Neues Leben, el Mücke-Bundes o los Deutschvölkische Monatshefte, los cuales publicaron números especiales en los que la NDSG desarrolló su actividad; aunque el caso más significativo fue, sin duda, el de Deutsche Freiheit. Este semanario, editado bajo el auspicio del NSDAP -fundado también en 1920- sacó a la luz un número monográfico dedicado a la nueva sociedad schopenhaueriana con el título Schopenhauer-Heft [Cuaderno-Schopenhauer] (1920). En él, Groener y Weber volvían a cargar contra la antigua SG, a la que acusaban de haber «desschopenhauerianizado a Schopenhauer», y manifestaban que la tarea de la NDSG era devolver a este filósofo su papel como verdadero educador de los alemanes.

La empresa ideológica proyectada por la NDSG culminó con la publicación de Gründungsbuch derNeuen Deutschen Schopenhauer-Gesellschaft [Librofundacional de la Nueva Sociedad-Schopenhauer Alemana] (1921) y de Werktstattbuch der Neuen Deutschen Schopenhauer-Gesellschaft [Actas de trabajo de la Nueva SociedadSchopenhauer Alemana] (1923), en los que se intentó sin éxito relegar a un segundo plano a la SG. Finalmente, en 1937 - un año después de la muerte de Groener- Emil Weber se vio obligado a disolver la sociedad debido a problemas de índole financiera. El final de la NDSG puso de manifiesto que esta sociedad -la cual apenas alcanzó el número de 50 afiliados ${ }^{18}$ - no tuvo éxito en su proyecto de convertir a Schopenhauer en el padre ideológico oficial del movimiento nazi ${ }^{19}$ ni siquiera en los años del auge del mismo y a pesar de intentos tan claros como el del Schopenhauer-Heft de 1920.

Aclarado el contexto de esta polémica, a continuación someteremos a análisis el panfleto que la desató: Schopenhauer und die Juden (1920). Tratar este texto es sin duda problemático, pero lo que aquí nos atañe es determinar si la expresión que en él encuentran el antisemitismo y el nacionalismo cultural alemán son únicamente un caso de manipulación ideológica o si, por el contrario, son también la herencia de un movimiento compensatorio identitario cuyas raíces puedan rastrearse, precisamente, hasta el éxito de la filosofía de Schopenhauer a mediados del siglo XIX. Para probar esta hipótesis mostraremos cómo el éxito de Schopenhauer supuso, tras la revolución frustrada de 1848, un movimiento compensatorio realizado por la burguesía alemana, del cual Eduard von Hartmann fue su continuador directo; y que finalmente, después de 1918, cristaliza de nuevo en los planteamientos antisemitas de Groener.

\section{EI nacionalismo cultural como movimiento compensatorio: El pesimismo de Schopenhauer y las sombras de 1848}

El nacionalismo cultural del que la concepción racista y antisemita de Maria Groener es en parte heredero hunde sus raíces y tiene su origen en el éxito de la propia filosofía de Arthur Schopenhauer a mediados del siglo XIX: el fracaso de la revolución liberal

\footnotetext{
16 A partir de ahora, NDSG.

17 Optamos aquí por mantener el término alemán, pues la expresión castellana movimiento popular no expresa adecuadamente el significado de esta rama de la llamada revolución conservadora, cuya dirección política siempre orbita en torno a los conceptos de raza y pueblo. (Cfr. Mohler 1989, pp. 131-138).

18 Cfr. Ciracì (2011a), p. 183.

19 Cfr. Ciracì (2011b), pp. 65 y s; Hansert (2010), p. 116.
} 
de 1848 y la consiguiente "renuncia" a la filosofía hegeliana transformaron a Arthur Schopenhauer en el filósofo "oficial" de la burguesía alemana. Esta adopción del pesimismo schopenhaueriano como nueva forma de identidad burguesa resultó ser en última instancia un movimiento compensatorio de la Bildungsbürgertum ${ }^{20}$ ante la frustración política ${ }^{21}$.

La filosofía hegeliana había fallado en su predicción de la progresiva realización de la Razón en la historia y también había incumplido su promesa de una "revolución sin revolución": en vez de la realización paulatina de la libertad a través del Estado, el resultado con el que se saldó el año 1848 fue el afianzamiento de la Restauración. El nacionalismo alemán liberal y constitucionalista, el cual había sido el espíritu vivificador de las aspiraciones políticas burguesas desde las guerras de liberación contra los franceses a principios del siglo XIX, vio todas sus expectativas defraudadas por el desarrollo de los acontecimientos históricos ${ }^{22}$.

El alivio para la frustración derivada de las aspiraciones políticas insatisfechas y para la resultante "crisis de identidad" de aquel nacionalismo lo encontró la Bildungsbürgertum en el espíritu pesimista de la filosofía de Schopenhauer: la burguesía alemana vio en él una explicación metafísica para el fracaso de la Revolución de Marzo y, al mismo tiempo, una justificación para abandonar cualquier empresa similar. En definitiva, el pesimismo fue una descarga y una compensación. Las palabras de John Oxenford en Iconoclasm of German Philosophy [La iconoclasia de la filosofía alemana] (1853) -sin duda, uno de los textos fundamentales que propiciaron el éxito popular de Schopenhauer-resultan especialmente esclarecedoras a este respecto:

Todo lo que una mente liberal aguarda con esperanza, si no con confianza-la extensión de los derechos políticos, la promoción de la educación, el hermanamiento de las naciones, el descubrimiento de nuevos métodos para controlar la testaruda naturaleza- debe ser abandonado como un sueño banal si alguna vez se acepta la doctrina de Schopenhauer. En una palabra: es un "pesimista" confeso. Lo es en su resultado sumario: que este es el peor de todos los mundos posibles, así que tampoco es susceptible de mejora; que lo mejor que podemos hacer es deshacernos de él totalmente [...]. (Oxenford 1853, p. 394).

Esto fue precisamente lo que la burguesía alemana abandonó. Una buena parte de la Bildungsbürgertum aceptó el siguiente reproche de Schopenhauer: «[...] el Miguel alemán se ha dejado convencer $[. .$.$] de que tiene que vestir un frac inglés [...] y$ ahora tiene un aspecto bastante ridículo con sus torpes maneras y su desmañado ser» (Schopenhauer (2009b), p. 274). ¿Cuál era este frac con el que los alemanes habían tratado, sin éxito, vestirse? Las formas de monarquía constitucional. Respecto a éstas, el filósofo del pesimismo advierte de lo siguiente a aquella burguesía decepcionada:

Estas formas, que han nacido del carácter y las circunstancias ingleses y suponen ambos, son acordes y naturales al pueblo inglés: pero también es natural al pueblo alemán estar dividido en muchos linajes sometidos a otros tantos príncipes $[\ldots]$, con un emperador por

20 La Bildungsbürgertum, entendida en términos sociológicos, estaría constituida por la burguesía alemana más o menos ilustrada del siglo xix.

21 Cfr. Löwith (2008), pp. 239 y s.; Lukács (1959), pp. 167-169; Eder (2003), p. 135; Lauxtermann (2000), pp. 231-234.

22 Cfr. Schulze (2011), pp. 101-104. 
encima de todos que mantiene la paz y representa la unidad del Imperio ante el exterior; porque eso ha nacido de su carácter y sus circunstancias. (Schopenhauer 2009b, p. 273).

El nacionalismo alemán no podía seguir los derroteros del constitucionalismo ni los de las aspiraciones políticas liberales. El éxito de la filosofía de Schopenhauer supuso el abandono de la confianza en la historia heredera de la Ilustración y la asunción resignada, en su lugar, de un destino trágico con el cual la burguesía alemana aceptaba los resultados prácticos del pesimismo. Así, el fracaso del nacionalismo liberal y constitucionalista, basado en una identidad burguesa de naturaleza política, fue compensado con un nacionalismo cultural caracterizado por un pesimismo en el que la Bildungsbürgertum encontraba una nueva forma de identidad alejada de los ideales políticos ${ }^{23}$.

\section{La construcción de la identidad y la dinámica amigo-enemigo: Eduard von Hartmann bajo la luz de 1871}

La cristalización de la identidad trágica burguesa como carácter nacional alemán, así como también la de sus consecuencias prácticas y políticas (la aceptación incondicional de un destino igualmente trágico), se llevó a cabo gracias a un heredero de Schopenhauer: Eduard von Hartmann. Este autor -casi olvidado por completo en la actualidad - fue sin duda el filósofo más exitoso del último tercio del siglo XIX en Alemania ${ }^{24}$; y en su obra capital, Philosophie des Ubewußten [Filosofía del inconsciente] (1869), pero sobre todo en Phänomenologie des sittlichen Bewusstsein [Fenomenología de la conciencia moral] (1878) fue donde se construyó de un modo sistemático el nacionalismo cultural alemán heredero directo de la recepción de Schopenhauer y su pesimismo. Lo que el éxito de Schopenhauer significó para la burguesía alemana, ésta lo encontró justificado científicamente en los trabajos del filósofo del inconsciente.

La filosofía de von Hartmann puede entenderse, a grandes rasgos, como una ampliación, sistematización y perfeccionamiento científicos de las intuiciones fundamentales de la filosofía schopenhaueriana: para él, en el fondo de la realidad no descansaba una voluntad irracional, sino un todopoderoso inconsciente nacido de un impulso volitivo ciego y originario del cual aquel debía liberarse mediante la adquisición de una mayor consciencia a lo largo de la historia. En esta suerte de panteísmo del inconsciente se aunaban, como dos caras de una misma moneda, un pesimismo eudemonológico y un optimismo evolucionista: la felicidad resultaba imposible por principio ${ }^{25}$, mas la progresiva adquisición de la conciencia de esta imposibilidad era, precisamente, el medio de la salvación universal y el fin último de la existencia fijado por el inconsciente ${ }^{26}$. Bajo esta concepción, la filosofía hartmanniana construyó el nacionalismo cultural alemán como la triple identidad entre cultura-pesimismo-Reich e introdujo en su seno la dinámica amigo-enemigo.

\footnotetext{
Cfr. Eder (2003), p. 136.

Cfr. Beiser (2016), p. 122-126; Heymons (1882), pp. 60 y s.

Cfr. von Hartmann (1873), pp. 665-669, 712 y 794.

Cfr. Ibid. pp. 749, 755 y s., y 763 .
} 
El optimismo evolucionista de von Hartmann exigía necesariamente aquel pesimismo eudemonológico: el darwinismo, según von Hartmann, había mostrado que la evolución sólo era posible mediante la lucha por la existencia, es decir, había confirmado científicamente que el camino hacia el fin último de la naturaleza, fijado por el inconsciente, estaba marcado por el sufrimiento y era imposible sin él. Aquel fin último de toda la existencia, para el cual -según von Hartmann- el darwinismo también daba suficientes pruebas científicas, no era otro que el desarrollo de la cultura humana, la elevación de la conciencia ${ }^{27}$ : la evolución de la especie, en el caso del ser humano, es entendida por Eduard von Hartmann como desarrollo y progreso de la cultura, el fruto más elevado de sus capacidades biológicas. Esta evolución, aunque cultural, se regía para el filósofo del inconsciente por las mismas leyes y mecanismos que la evolución de las especies animales: una lucha por la existencia en la que la muerte de millones por la guerra, la miseria, el crimen o la injusticia, es para la providencia del inconsciente únicamente «la almajara, el abono de la cultura» (von Hartmann s.f., p. 526).

Así, von Hartmann entiende que la primera condición necesaria para el desarrollo cultural es la desigualdad social, ya que «desde un punto de vista evolucionista la desigualdad o diferenciación creciente de la organización social es la condición sin la cual la cultura es impensable» (von Hartmann s.f., p. 540 y s.). Junto a esta condición necesaria para la existencia de una aristocracia espiritual que, liberada de la carga de la preocupación por la existencia, desarrolle la cultura, von Hartmann establece los medios por los que ésta debe desarrollarse: por una parte, guerra y colonización, pues son «el medio principal de la lucha de razas [Racenkampfes], es decir, de la selección reproductiva de la humanidad» (von Hartmann s.f., p. 534); y por otra, la competencia económica entre individuos, grupos mercantiles y pueblos, ya que ésta, a pesar de la miseria que conlleva, es «el móvil más poderoso para el esfuerzo más potenciado de la dedicación y de la inteligencia» (von Hartmann s.f., p. 538). El optimismo evolucionista de Eduard von Hartmann resultaba ser, en el fondo, un pesimismo potenciado: la aceptación del darwinismo social y del destino trágico. Y, en última instancia, suponía la identificación entre cultura y pesimismo.

Ahora bien, ¿cómo se llega a identificar estos dos elementos con el Segundo Reich? La dinámica amigo-enemigo que Eduard von Hartmann introduce en su concepción de la cultura es la que hizo de su filosofía un espejo legitimador del Reich bismarckiano: si el ser humano se ve siempre obligado a elegir entre «la promoción de la felicidad a costa del desarrollo cultural o la promoción del desarrollo cultural a costa de la felicidad humana» (von Hartmann s.f., p. 521), entonces quien se decante por la primera alternativa será para von Hartmann un enemigo de la cultura. Bajo esta óptica, von Hartmann rescata a finales de los años 70 del siglo XIX el término Kulturkampf y lo erige como deber moral del ser humano: «En última instancia, la moralidad es la lucha cultural [Culturkampf], es decir, significa luchar y combatir por el sostenimiento y elevación de la cultura. [...] Todos estamos llamados a tomar partido en esta lucha» (von Hartmann s.f., p. 533). Entre estos enemigos de la cultura, von Hartmann sitúa el liberalismo utilitarista, el jesuitismo y la socialdemocracia; los cuales buscan aumentar la felicidad general luchando contra el orden social y estatal establecido (el Reich de Bismarck) ${ }^{28}$. Para von Hartmann, con ello solo se

\footnotetext{
Cfr. von Hartmann (1873), p. 642.; von Hartmann (s.f.), pp. 522-526.

Cfr. von Hartmann (s.f.), pp. 516-518; Beiser (2016), p. 161.
} 
conseguiría una animalización y estupidización del ser humano que trae nefastas consecuencias para el desarrollo de la cultura: para el filósofo del inconsciente, las exigencias de igualdad demandadas por estos "enemigos" de la cultura no son más que una justificación de la mediocridad.

Teniendo en cuenta los supuestos teóricos de la filosofía de Eduard von Hartmann y el asombroso éxito editorial del que disfrutó este autor a finales del XIX, no resulta difícil comprender cómo la burguesía alemana abrazó esta triple identificación constitutiva del nacionalismo cultural alemán: descargados de historia pero colmados de destino trágico, los burgueses alemanes más o menos conservadores pudieron verse a sí mismos como los Kulturkämpfer [luchadores de la cultura] hartmannianos que debían proteger, fomentar y desarrollar esa cultura, aun a costa del sufrimiento -también del propio. Por ello no consideramos desatinado afirmar que la filosofía de von Hartmann fue el "humus cultural" en el que afloró el entusiasmo con el que se aplaudió el comienzo de la Primera Guerra Mundial como un suceso histórico necesario y casi escatológico: el pesimismo, transformado en destino trágico, hizo de la certeza y de la necesidad moral del sufrimiento una suerte de pulsión colectiva de muerte; y de la Gran Guerra, un acontecimiento que venía a purgar y depurar la cultura.

\section{Nacionalismo cultural en clave antisemita: Maria Groener y la lectura racista de Schopenhauer después de la Primera Guerra Mundial}

La derrota alemana en la Gran Guerra, así como la fragilidad y el estado volátil de la República de Weimar fueron, sin duda, la ocasión de reeditar o revivificar el motivo compensatorio que tras la decepción postrevolucionaria de 1848 había llevado a la burguesía alemana a abrazar el pesimismo de Schopenhauer como su "filosofía oficial". El modelo de von Hartmann y sus estándares no eran ya en modo alguno apropiados para el resultado final de 1918: ¿cómo mantener ese nacionalismo cultural, la Kultur en un sentido estrictamente hartmanniano, después del desastre? El retorno a la filosofía de Schopenhauer por parte de ultranacionalistas como Groener no parece casual, ya que el sabio de Frankfurt aparece en los primeros años de la República de Weimar del mismo modo que lo hizo en 1848: en una situación de crisis de identidad alemana. Entonces aquella crisis era la basada en un nacionalismo liberal constitucional; ahora, la apoyada en un nacionalismo cultural en clave imperialista.

Con la lectura racista del filósofo del pesimismo realizada en Schopenhauer und die Juden (1920), Groener trataba de acreditar de nuevo, a pesar del desastre de la derrota en la Primera Guerra Mundial, la viabilidad un nacionalismo basado en la idea de Kultur y su identidad con el pesimismo. El movimiento compensatorio realizado por Groener consistía en desplazar del exterior al interior aquello que ponía en cuestión el nacionalismo cultural alemán: no la derrota ante las potencias extranjeras, sino un enemigo interno, el judaísmo, era lo que amenazaba la identidad alemana; y lo hacía -en palabras de la autora- envenenando la «germanidad», su carácter trágico y pesimista. En este juego de compensación, identificación del enemigo y construcción de la propia identidad es donde se dan cita, por una parte, la herencia de ese nacionalismo cultural que tiene su origen en la recepción de Schopenhauer y, por otra, la manipulación ideológica racista y antisemita. 
Que la verdadera amenaza para la identidad alemana era el judaísmo, lo acredita Groener alegando que todos los grandes espíritus de Alemania, entre los que se encontraría Schopenhauer, se habían ocupado de un modo u otro de la «cuestión judía ${ }^{29}$. Fundiendo y confundiendo algunos pasajes sobre los judíos provenientes de la obra del sabio de Frankfurt, su teoría de la invariabilidad del carácter y las tesis de los ideólogos de la higiene racial, Groener establece la tesis de que el «carácter alemán», la «germanidad», se encuentra en peligro de «judaizarse»y, con ello, perder su esencia e identidad pesimistas.

Para justificar esto, Groener formula una teoría del carácter nacional -piedra angular de su panfleto- en la que extrapola de los individuos a los pueblos las líneas fundamentales de la teoría schopenhaueriana del carácter inteligible. En este movimiento la autora no sólo irá más allá del pensamiento de Arthur Schopenhauer, sino que ignorará algunos de los corolarios más relevantes de su filosofía para poder llevar a cabo su ejercicio de manipulación ideológica. Veamos esto con más detenimiento.

Si bien es cierto que el filósofo del pesimismo llega a utilizar en sus escritos el término "carácter nacional [Nationalcharakter]»" ${ }^{30}$, no es menos cierto que el uso, el significado y el alcance del mismo dentro de su sistema filosófico desacreditan por completo la interpretación que Groener hace de él. Quizás el pasaje que mejor expresa el verdadero significado de este término para Schopenhauer sea el siguiente:

[...] la individualidad prevalece ampliamente sobre la nacionalidad, y en un hombre dado merece mil veces mayor consideración que ésta. El carácter nacional, puesto que habla de la multitud, nunca se puede elogiar honradamente en gran medida. Antes bien, la limitación, el absurdo y la maldad humanos se manifiestan de forma diferente en cada país, y a eso se le llama carácter nacional. (Schopenhauer 2009a, p. 378).

De las palabras de Schopenhauer parece desprenderse que la expresión carácter nacional refiere al conjunto de circunstancias, de usos y costumbres que sirven de ocasión en un país determinado para la expresión de los caracteres individuales. Sea como fuere, lo que está claro es que para Schopenhauer este término tiene un valor relativo y está ligado en todo caso a consideraciones de tipo prudencial o de sabiduría mundana; y no a reflexiones de naturaleza ética o política cuidadosamente deducidas de los principios fundamentales de su filosofía. Esto se deja ver claramente cuando el filósofo de pesimismo sostiene lo siguiente:

[...] se afirma que la ética no tiene como objeto el obrar de los individuos sino el de los pueblos, y que solo ese es un tema digno de ella. Nada puede ser más equivocado que esa opinión, basada en el más bajo realismo. Pues en cada individuo se manifiesta completa e indivisa la voluntad de vivir, el ser en sí; y el microcosmos es igual que el macrocosmos. Las masas no tienen más contenido que cada uno de los individuos. En la ética no se trata de la acción y el resultado sino del querer, y el querer se da únicamente en el individuo. No se decide moralmente el destino de los pueblos, que existe solo en el fenómeno, sino el del individuo. En realidad los pueblos son meras abstracciones: solo los individuos existen realmente. (Schopenhauer 2005, p. 647).

\footnotetext{
Cfr. Groener (1920), p. 5.
}

30 Cfr. Schopenhauer (2009a), p. 378; Schopenhauer (2009b), p. 279 y s. 
El significado de este texto proveniente del segundo volumen de El mundo como voluntad y representación es de gran importancia para comprender hasta qué punto la lectura que Maria Groener hace del pensamiento de Arthur Schopenhauer es un auténtico ejercicio de prestidigitación filosófica con el único objetivo de propugnar el antisemitismo. El sabio de Frankfurt - tal y como ha señalado muy acertadamente Max Horkheimer ${ }^{31}$ - es un nominalista en todo lo referente al tratamiento teórico de la sociedad: «[...] así como en la naturaleza solo la especie es real y los genera son meras abstracciones» -reitera el filósofo del pesimismo- «en el género humano solo los individuos y su curso vital son reales, los pueblos y su vida son meras abstracciones» (Schopenhauer 2005, p. 494). En resumidas cuentas: los pueblos o las naciones son conceptos.

Para Schopenhauer, los conceptos, como universalia post rem ${ }^{32}$, no son más que «el reflejo abstracto de lo intuitivo» ${ }^{33}$. Entendidos como una forma de conocimiento, son «un tipo de representación sumamente imperfecto» ${ }^{34}$, una suerte de "representaciones de representaciones"; y contemplados desde un punto de vista metafísico, poco más que fantasmagorías: la naturaleza abstracta del concepto hace que éste no sea «casi nada más que una palabra» $\rangle^{35}$.

Ignorando estas consideraciones, Groener transforma el concepto de nación en un fenómeno de la representación cuyo grado de existencia es equiparable al de los individuos, permitiéndose con ello hablar también de la existencia del carácter nacional en los mismos términos que del carácter individual. Como es bien sabido, en la filosofía schopenhaueriana las ideas platónicas, como representaciones adecuadas de la voluntad ${ }^{36}$, son desde un punto de vista cognoscitivo «el objeto de conocimiento real» ${ }^{37}$; y desde uno metafísico, los universalia ante rem $^{38}$ que en nada se diferencian de la voluntad excepto en que caen bajo la forma general del conocer, la de sujeto-objeto ${ }^{39}$. Las ideas son los arquetipos inmutables y eternos de lo que en el fenómeno es contemplado como plural y en constante devenir, es decir, de los individuos: a cada fuerza natural, a cada especie vegetal y animal le corresponde una idea, la cual expresa un determinado afán de la voluntad de vivir ${ }^{40}$. Sin embargo, en el caso del ser humano cada individuo es el fenómeno de una idea particular, la cual es considerada como su carácter. En este sentido, Schopenhauer afirma: «El carácter de cada hombre particular, en la medida que es individual y no se halla totalmente comprendido en el de la especie, puede ser considerado como una idea especial correspondiente a un acto peculiar de objetivación de la voluntad. Ese acto mismo sería entonces su carácter inteligible» (Schopenhauer 2004, p. 213). Este carácter inteligible es la idea platónica en la que se destila la invariable esencia de cada ser humano particular.

Esto también es trasladado por Groener de los individuos a los pueblos: si para ella las naciones dejan de ser una mera abstracción y pasan a convertirse en un

\footnotetext{
Cfr. Horkheimer (1989), p. 123.

Cfr. Schopenhauer (2005), p. 412.

Cfr. Schopenhauer (2004), p. 85.

Cfr. Schopenhauer (2005), p. 177.

Cfr. Ibid., p. 93.

Cfr. Schopenhauer (2004), pp. 214 y s.

Cfr. Ibid., p. 226.

Vid. supr., nota 31.

Cfr. Schopenhauer (2004), p. 229.

Cfr. Ibid., p. 182.
} 
fenómeno que tiene existencia real en la representación, entonces cada una ellas sería la manifestación de una idea eterna; y por lo tanto, al igual que ocurre con los seres humanos, a cada nación particular le correspondería un carácter nacional específico. Llegados a este punto, Groener entiende que el carácter nacional, en tanto que idea, tiene los mismos rasgos que Schopenhauer atribuye al carácter inteligible en el caso del ser humano: éste tiene que ser «individual», es decir «diferente en cada uno»; solo puede ser conocido de modo «empírico», pues «[ú]nicamente por experiencia llega uno a conocer[lo]»; es también «constante», ya que permanece «inmutable y siempre el mismo»; y además es «innato» porque «no es resultado del artificio ni de las circunstancias sometidas al azar; sino que es obra de la naturaleza misma» ${ }^{41}$. Una vez asumido esto, aplicándolo al caso de las naciones, Groener no duda en afirmar lo siguiente: «"Los judíos siempre serán judíos” dice Schopenhauer a los benefactores de la humanidad. Por eso iguardaos bien de ellos! [Pero] él también dice a los temerosos “¡Los germanos siempre serán germanos!", así que no os asustéis» (Groener 1920, p. 10).

Con este exceso interpretativo, la autora del panfleto antisemita se ve autorizada a describir los rasgos de los caracteres nacionales alemán y judío recurriendo a las consideraciones schopenhauerianas sobre el cristianismo y el judaísmo interpretándolas en clave racial: la religión -afirma Groener-es el mejor «termómetro» del carácter nacional ${ }^{42}$. En última instancia, lo que hace Maria Groener aquí no es otra cosa que convertir la religión una suerte de equivalente nacional del carácter empírico individual.

El carácter empírico es para el sabio de Frankfurt el fenómeno del carácter inteligible, es decir, el conjunto acciones que, llevadas a cabo por un ser humano a lo largo del tiempo, revelan y permiten conocer su carácter en virtud del principio operari sequitur esse $e^{43}$. Pero si para Arthur Schopenhauer «[e]l curso de la vida produce la imagen del carácter empírico, cuyo original es el inteligible» (Schopenhauer 2004, p. 428); para Groener las religiones son las que ofrecen un conocimiento fidedigno, aunque empírico, del carácter nacional. Así, sirviéndose de la distinción schopenhaueriana entre religiones optimistas y pesimistas, la autora antisemita dotará de contenido a los caracteres nacionales germano y judío.

Arthur Schopenhauer establece una estrecha relación entre el optimismo y el judaísmo basándose en el siguiente pasaje del Génesis: "Y vio Dios todo lo que había hecho, y he aquí que era bueno en gran manera» (Génesis 1:31). De este aserto se sigue, según Schopenhauer, que la visión del mundo veterotestamentaria, la cual constituye la esencia del judaísmo, es por necesidad optimista: una inteligencia ha creado el mundo conforme a la razón y, por lo tanto, éste es bueno ${ }^{44}$. Por el contrario, el verdadero cristianismo es pesimista, ya que en la figura de Jesucristo se expresa la necesidad de negar y redimir un mundo que es esencialmente malo. Por ello, Schopenhauer afirma: «Lo que siempre se opone a esa visión auténticamente

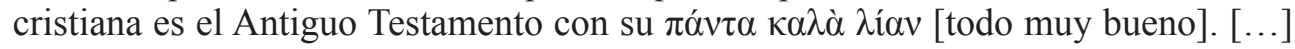
[E]l judaísmo con su optimista relato de la Creación [...] contradice la tendencia a negar el mundo presente en el Nuevo Testamento» ${ }^{45}$ (Schopenhauer 2005, p. 677).

41 Cfr. Schopenhauer (2009c), pp. 85-90.

42 Cfr. Groener (1920), p. 21.

43 Cfr. Schopenhauer (2009c), p. 220; Schopenhauer (2004), pp. 210 y 350.

44 Cfr. Schopenhauer (2005), p. 634.

45 En este mismo sentido se expresa Schopenhauer en: Schopenhauer (2005), pp. 681 y s., y 703 y s.; Schopenhauer 
Así, bajo esta diferenciación entre religiones optimistas y pesimistas, la autora del panfleto antisemita establece el rasgo fundamental de los caracteres nacionales judío y alemán, y en ese sentido afirma:

El auténtico pesimismo filosófico en el sentido y espíritu de la filosofía de Schopenhauer es un estado de ánimo mundano [Weltstimmung] ario que se contrapone al judío. El pesimismo es la comprensión de que en esta vida terrena se da más dolor que felicidad; que debemos estar agradecidos por la alegría y por la suerte, y por ello, que no debemos desesperar del dolor, sino acostumbrarnos a él; que no debemos perseguir unilateralmente la dicha, sino [aprender a] cargar con las penas. Todo hombre profundo, todo ario, es en el fondo de su corazón un pesimista en sentido schopenhaueriano: un redentor. (Groener 1920, p. 23).

Con esto, Groener dota al carácter nacional alemán de todas las virtudes del héroe schopenhaueriano y su tragedia al tiempo que carga sobre el carácter nacional judío todos los rasgos moralmente reprobables del optimismo "filisteo": «El optimista desea ante todo ser dichoso y rico; el pesimista, ver a los demás dichosos y ricos» (Groener 1920, p. 23).

Establecida esta tipología de caracteres nacionales, la autora antisemita fija la tarea que debe llevar a cabo la «germanidad»; tarea que constituirá, en el caso de Groener, el núcleo del nuevo movimiento compensatorio del nacionalismo cultural alemán en el contexto de la posguerra. ¿Qué tarea puede ser ésta si el carácter es, desde los presupuestos schopenhauerianos, invariable?; ¿no es acaso la filosofía de Schopenhauer quietista por principio? Groener transforma en este punto las observaciones schopenhauerianas sobre el carácter adquirido en un discurso de la autenticidad en clave racial: mientras que el carácter adquirido es para Schopenhauer el conocimiento del propio carácter invariable a través de la experiencia $\mathrm{y}$, en consecuencia, no es otra cosa que aprender a no esperar de uno mismo más de lo que se es ${ }^{46}$; Groener lo convierte en un conocimiento del carácter nacional que implica la tarea heroica, todavía no realizada por los alemanes, de dar cumplimiento a ese carácter. Según Groener, Alemania debe orientar todo su trabajo, todo su esfuerzo y toda su fuerza al autoconocimiento de su Nationalcharakter. Por ello afirma: «Somos espoleados al estudio de nuestro carácter, al esfuerzo de ajustarnos a él, a quitar el velo que lo cubre, a guardarlo de los peligros y a fortalecerlo en la lucha» (Groener 1920, p. 13). Desde este punto de vista, Groener propone la filosofía de Schopenhauer como una herramienta que puede permitir el desarrollo de un órgano espiritual que «distinga amigos y enemigos en torno a la cuestión judía» (Groener 1920, p. 37), y que es capaz de garantizar al pueblo germano la «conservación espiritual de su raza» (Groener 1920, p. 27).

\section{Conclusión}

Schopenhauer und die Juden (1920) de Maria Groener fue una suerte de manifiesto que condensaba las aspiraciones e ideas que estuvieron a la base de la fundación de

(2009a), p. 96; Schopenhauer (2009b), pp. 316 y 390-398; VV.AA. (2016), p. 276.

46 Cfr. Schopenhauer (2009c), p. 87; Schopenhauer (2004), pp. 360-364. 
la NDSG en los años veinte del siglo pasado. Como hemos visto, este panfleto no solo es un ejemplo de manipulación ideológica del pensamiento de Schopenhauer al servicio de la völkische Bewegung, sino también el desarrollo de una determinada concepción del nacionalismo cultural alemán en la que, finalmente, el antisemitismo encuentra un lugar adecuado en el que instalarse.

Respecto a esto último, queda aclarar que el antisemitismo que se extiende con virulencia en la época de la República de Weimar no se restringe a ella ni es una tendencia exclusiva de sociedades como la NDSG o de autores como Maria Groener: León Poliakov muestra en el cuarto volumen de su monumental Historia del antisemitismo que la explosión de la propaganda antisemita contemporánea en Alemania comienza con la fundación del Segundo Reich y se convierte en una bandera bajo la cual encuentra cobijo una buena parte de las élites guillerminas de finales del siglo $\mathrm{XIX}^{47}$. En este sentido, el texto de Groener y otros de la NDSG solo representan una reactivación ${ }^{48} \mathrm{y}$ un nuevo episodio de aquella tendencia.

Sin embargo, a pesar de que los planteamientos groenerianos pueden ser considerados como una ocasión entre otras muchas para la expresión del antisemitismo en la época de la República de Weimar, debemos señalar aquí lo que en estos planteamientos resulta especifico. Por su significado como respuesta a aquella crisis de identidad resultado de la derrota en la Gran Guerra, como movimiento compensatorio del nacionalismo cultural alemán, las tesis groenerianas reciben su carácter específico en virtud de lo siguiente: a través de su lectura del pesimismo schopenhaueriano y su identificación con lo «germano», Groener hace del antisemitismo un rasgo esencial de la identidad alemana. Ya no se trataba únicamente de que, desde el punto de vista de la völkische Bewegung, la identidad alemana tuviese que desarrollarse mediante el antisemitismo, sino que mediante la transformación de la distinción schopenhaueriana entre optimismo y pesimismo llevada a cabo por Groener ser alemán era sinónimo de ser antisemita.

Esta nueva construcción groeneriana de la identidad alemana, heredera nacionalismo cultural resultado del movimiento compensatorio que motivó tanto la recepción de Schopenhauer como el éxito de von Hartmann en la segunda mitad del siglo XIX, no fue posible, tal y como señalamos, sin un componente de manipulación.

En relación a la tergiversación del pensamiento de Schopenhauer, hemos tratado de mostrar hasta qué punto Maria Groener ignoró deliberadamente aspectos fundamentales de la filosofía del sabio de Frankfurt y cómo realizó un exceso interpretativo de algunos de sus conceptos con la clara intención de convertir a este filósofo en el padre ideológico de los movimientos antisemitas alemanes de comienzos del siglo xx e incluso del partido nazi. Sin embargo, resta la cuestión: ¿hasta qué punto hay motivos antisemitas en la filosofía de Arthur Schopenhauer? Esta pregunta es difícil de responder $y$, sin duda, requeriría de un tratamiento más extenso del que nosotros ofreceremos en esta conclusión. A pesar de ello, consideramos necesario hacer algunas aclaraciones a este respecto con el fin de iluminar este oscuro episodio de la historia de la filosofía schopenhaueriana.

47 Cfr. Poliakov (1981), pp. 32-41.

48 El antisemitismo que creció exponencialmente en torno a la década de los setenta del siglo XIX fue sofocándose en los últimos años del siglo XIX por el desplazamiento del interés general hacia la ambición imperialista y colonial de Alemania; y llegó a convertirse incluso en simpatía hacia la población judía alemana a causa de su participación en estallido de patriotismo generalizado al comienzo de la Primera Guerra Mundial. (Cfr. Poliakov 1981, pp. 43-45 y 165-170). 
Leon Poliakov ha descrito a Schopenhauer como una suerte de arquetipo de filósofo antisemita ${ }^{49}$. Sin duda, en Schopenhauer existe una serie de caracterizaciones de los judíos, como la realizada en el $\$ 135$ del segundo volumen de Parerga y Paralipómena, que son muestra y expresión de un antisemitismo que, por otra parte, como también el propio Poliakov reconoce, no es un patrimonio exclusivo de Schopenhauer ni de la Alemania decimonónica, sino más bien una moneda de cambio común en Europa ${ }^{50}$. Sin embargo, tiene razón Alexis Philonlenko al afirmar que en las valoraciones acerca de la cuestión del antisemitismo en la filosofía schopenhaueriana se ha dictado con frecuencia «un juicio falseado por una lógica retrospectiva, respetable sin duda alguna con respecto a nuestra abominable historia, pero discutible especulativamente» (Philonlenko 1989, p. 191).

Sin necesidad de tratar de evadir un juicio sobre las apreciaciones antisemitas del filósofo del pesimismo, la cuestión fundamental aquí debe ser explicarlas: sin temor a equivocarnos, una buena parte de ellas -sobre todo las más duras y reprochablesresponden en buena medida al ambiente literario y filosófico de la Alemania del siglo XIX que muy bien ha sabido presentar Poliakov en su obra ${ }^{51}$. Ahora bien, la posición estrictamente filosófica de Schopenhauer respecto al judaísmo, tal y como ha señalado con acierto Philonlenko, responde a la cuestión de la «concepción ética del mundo en el pensamiento judío» (Philonlenko 1989, p. 192). Más allá del problema que presenta valorar el conocimiento más o menos preciso que Schopenhauer tuvo del judaísmo, las críticas vertidas sobre éste se centran en la distinción schopenhaueriana entre filosofías optimistas y pesimistas, siendo las primeras aquellas que justifican la existencia de un mundo que, a la luz de la metafísica hermenéutica del sabio de Frankfurt, es el peor de los posibles y, en virtud de ello, sería mejor que no existiese en absoluto. En este sentido, las palabras del propio Arthur Schopenhauer despejan toda duda al respecto:

En el fondo, el optimismo es el injustificado autoelogio del verdadero autor del mundo, la voluntad de vivir, que se refleja complacida en su obra: en consecuencia, no solo es una teoría falsa sino también funesta. Pues nos presenta la vida como un estado deseable y pone como fin de la misma la felicidad. Partiendo de ahí, cada cual cree estar plenamente justificado para exigir la felicidad y el placer [...]; pero es mucho más acertado considerar que el fin de nuestra vida es el trabajo, la privación, la miseria y el sufrimiento, coronados por la muerte (tal y como hacen el brahmanismo y el budismo, y también el auténtico cristianismo); porque eso es lo que conduce a la negación de la voluntad de vivir. (Schopenhauer 2004, p. 639).

A la luz de esto, resulta todavía más evidente la manipulación del pensamiento de Schopenhauer llevada a cabo por Groener y la NDSG; a la cual la SG y algunos de sus miembros más relevantes, como Hans Zint y Frank Mockrauer, se opusieron con firmeza no solo en defensa del estudio científico y riguroso de la filosofía del sabio de Frankfurt, sino también con el propósito de preservar el espíritu fundacional que Deussen insufló a la sociedad schopenhaueriana. Para ellos, al igual que para nosotros, estaba fuera de toda duda y discusión que, en torno a la cuestión del

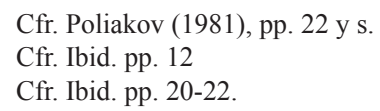


judaísmo, Schopenhauer nunca se expresó en los términos «psicofisiognómicos» en los que lo hizo Groener, propios -en palabras de Poliakov- de una «filosofía ${\text { veterinaria }{ }^{52}}^{52}$ que se presenta en el panfleto de la autora antisemita como un oscuro presagio, ya en los años veinte, de la barbarie del nazismo.

\section{Referencias bibliográficas}

Beiser, F. C. (2016): Weltschmerz. Pessimism in German Philosophy, Oxford, Oxford University Press.

Ciracì, F. (2011a): «Die Neue Deutsche Schopenhauer-Gesellschaft in der Zwanziger- und Dreißigerjahren», en Schopenhauer-Jahrbuch, 92, 2011, pp. 170-191.

Ciracì, F. (2011b): In lota per Schopenhauer. La Schopenhauer-Gesellschaft tra ricerca filosófica e manipolacione ideologica 1911-1948, Pisa, Pensa Multimedia.

Deussen, P. (1911): «Wie ich zu Schopenhauer kam», en Schopenhauer-Jahrbuch, 1, pp. 13-18.

Eder, J. (2003): «Schopenhauer-Rezeption nach 1848», en Bunyan, A. y Koopmann, H. (Eds.): Kulturkritik, Erinnerungskunst und Utopie nach 1848. Deutsche Literatur und Kultur von Nachmärz bis zur Gründerzeit in europäischer Perspektive II, Bielefeld, Aisthesis Verlag, pp. 133-148.

Groener, M. (1916): «Die vierte Jahrbuch der Schopenhauer Gesellschaft», en: Archiv für Geschichte der Philosophie, 29/2, pp. 133-143.

Groener, M. (1920): Schopenhauer und die Juden, München, Deutsche Volksverlag.

Hansert, A. (2010): Schopenhauer im 20. Jahrhundert, Böhlau Verlag, Wien-Köln-Weimar.

von Hartmann, E. (s.f.): «Das sittliche Bewusstsein. Eine Entwickelung seiner mannigfaltigen Gestalten in ihrem inneren Zusamenhange mit besonderer Rücksicht auf brennende sociale und kirchliche Fragen der Gegenwart. Zweite, durchgesehene Auflage», en von Hartmann, E.: Eduard von Hartmann's Ausgewälte Werke. Bd. 2, Leipzig, Wilhelm Friedrich.

von Hartmann, E. (1873): Philosophie des Ubewußten, Berlín, Carl Duncker's Verlag.

Heymons, C. (1880): Eduad von Hartmann. Erinnerungen aus den Jahren 1868-1881, Berlín, Carl Duncker's Verlag.

Horkheimer, M. (1989): «Schopenhauer y la sociedad», en Adorno, T. y Horkheimer, M.: Sociológica, Madrid, Taurus, pp. 119-129.

Lauxtermann, P. F. H. (2000): Schopenhauer's Broken World View. Colours and Ethics between Kant and Goethe, Dordrecht, Springer Science+Business Media.

Löwith, K. (2008): De Hegel a Nietzsche. La quiebra revolucionaria del pensamiento en el siglo XIX, Buenos Aires, Katz Editores.

Lukács, G. (1959): El asalto a la Razón. La trayectoria del irracionalismo desde Schelling hasta Hitler, México-Buenos Aires, F.C.E.

Mohler, A. (1989): Die Konservative Revolution in Deutschland. 1918-1932. Ein Handbuch, Dramstadt, Wissenschaftliche Buchgesellshaft.

Oxenford, J. (1853): «Iconoclasm in German Philosophy», en The Westminster Review, 3, pp. $388-407$.

Philonlenko, A. (1989): Schopenhauer: una filosofia de la tragedia, Madrid, Anthropos.

Poliakov, L. (1981): Historia del antisemitismo. La Europa suicida: 1870-1933, trad. Josep Elias, Barcelona, Muchnik Editores.

52 Cfr. Poliakov (1981), p. 28. 
Schopenhauer, A. (2004): El mundo como voluntad y representación I, trad. Pilar López de Santa María, Madrid, Trotta.

Schopenhauer, A. (2005): El mundo como voluntad y representación II, trad. Pilar López de Santa María, Madrid, Trotta.

Schopenhauer, A. (2009a): Parerga y paralipómena I, trad. Pilar López de Santa María, Madrid, Trotta.

Schopenhauer, A. (2009b): Parerga y paralipómena II, trad. Pilar López de Santa María, Madrid, Trotta.

Schopenhauer, A. (2009c): Los dos problemas fundamentales de la ética, trad. Pilar López de Santa María, Madrid, Siglo XXI.

Schulze, H. (2011): Breve historia de Alemania, Madrid, Alianza.

VV.AA. (2016): Conversaciones con Arthur Schopenhauer. Testimonios sobre la vida y la obra del filósofo pesimista, trad. Luis Fernando Moreno Claros, Barcelona, Acantilado. 